Article

\title{
Polyisobutylene-Based Thermoplastic Elastomers for Manufacturing Polymeric Heart Valve Leaflets: In Vitro and In Vivo Results
}

\author{
Evgeny Ovcharenko ${ }^{1, *}$, Maria Rezvova ${ }^{1}\left(\mathbb{0}\right.$, Pavel Nikishau ${ }^{2,3}$, Sergei Kostjuk ${ }^{2,3,4}(\mathbb{0}$, \\ Tatiana Glushkova ${ }^{1}$, Larisa Antonova ${ }^{1}{ }^{1}$, Dmitry Trebushat ${ }^{5}$, Tatiana Akentieva ${ }^{1}$, \\ Daria Shishkova $^{1}$, Evgeniya Krivikina ${ }^{1}$, Kirill Klyshnikov ${ }^{1}{ }^{\circledR}$, Yulia Kudryavtseva ${ }^{1}$ and \\ Leonid Barbarash ${ }^{1}$ \\ 1 Research Institute for Complex Issues of Cardiovascular Diseases, 650002 Kemerovo, Russia; \\ rezvovamaria@mail.ru (M.R.); bio.tvg@mail.ru (T.G.); antonova.la@mail.ru (L.A.); \\ t.akentyeva@mail.ru (T.A.); shishkovadk@gmail.com (D.S.); leonora92@mail.ru (E.K.); \\ klyshnikovk@gmail.com (K.K.); jackie1970@mail.ru (Y.K.); director@kemcardio.ru (L.B.) \\ 2 Research Institute for Physical Chemical Problems of the Belarusian State University, 220030 Minsk, Belarus; \\ Nikishau@bsu.by (P.N.); kostjuks@bsu.by (S.K.) \\ 3 Faculty of Chemistry, Belarusian State University, 220030 Minsk, Belarus \\ 4 Institute of Regenerative Medicine, Federal State Autonomous Educational Institution of Higher Education \\ I.M. Sechenov First Moscow State Medical University of the Ministry of Health of the Russian \\ Federation (Sechenov University), 119991 Moscow, Russia \\ 5 OOO Angiolain, 630090 Novosibirsk, Russia; d.trebushat@angioline.ru \\ * Correspondence: ov.eugene@gmail.com; Tel.: +738-4264-4527
}

Received: 30 September 2019; Accepted: 5 November 2019; Published: 8 November 2019

Featured Application: The assessment of SIBS physical properties and hemocompatibility ensures the optimal choice of nanofillers or the introduction of a new molecule to eliminate its tendency towards viscoelastic creeping and poor strength. Obtained data have put the path forward in synthesizing superior material for manufacturing polymeric heart valve leaflets.

\begin{abstract}
Superior polymers represent a promising alternative to mechanical and biological materials commonly used for manufacturing artificial heart valves. The study is aimed at assessing poly(styrene-block-isobutylene-block-styrene) (SIBS) properties and comparing them with polytetrafluoroethylene (Gore-tex ${ }^{\mathrm{TM}}$, a reference sample). Surface topography of both materials was evaluated with scanning electron microscopy and atomic force microscopy. The mechanical properties were measured under uniaxial tension. The water contact angle was estimated to evaluate hydrophilicity/hydrophobicity of the study samples. Materials' hemocompatibility was evaluated using cell lines (Ea.hy 926), donor blood, and in vivo. SIBS possess a regular surface relief. It is hydrophobic and has lower strength as compared to Gore-tex ${ }^{\mathrm{TM}}$ (3.51 MPa vs. 13.2/23.8 MPa). SIBS and Gore-tex ${ }^{\mathrm{TM}}$ have similar hemocompatibility (hemolysis, adhesion, and platelet aggregation). The subcutaneous rat implantation reports that SIBS has a lower tendency towards calcification $(0.39 \mathrm{mg} / \mathrm{g})$ compared with Gore-tex ${ }^{\mathrm{TM}}(1.29 \mathrm{mg} / \mathrm{g})$. SIBS is a highly hemocompatible material with a promising potential for manufacturing heart valve leaflets, but its mechanical properties require further improvements. The possible options include the reinforcement with nanofillers and introductions of new chains in its structure.
\end{abstract}

Keywords: polymeric heart valve leaflets; ABA block copolymers of isobutylene and styrene; biostability; hemocompatibility; physical and mechanical properties 


\section{Introduction}

Valvular heart disease is a major cause of disability and premature mortality worldwide [1]. Clinically moderate or severe valvular heart disease will double before 2050 from 1.5 million in 2015 to 3.3 million in 2056 [2] resulting in a sharp increase of heart valve replacements, either surgical or transcatheter. To date, damaged native valves are replaced with mechanical and tissue heart valves. However, neither mechanical nor tissue prostheses are ideal [3,4]. Their implantation is associated with reduced quality of life. Mechanical prostheses require life-long anticoagulation therapy and are associated with a substantially high risk of bleedings [5]. Tissue heart valves are susceptible to calcification and degeneration resulting in the structural failure, requiring repeat surgery $[6,7]$. Numerous approaches have been proposed to solve the existing problem and develop a durable heart valve: tissue-engineering and hybrid materials [8-10], novel shape memory designs and magnetically triggered devices [11], bioinert ceramics [12], and polymeric materials with enhanced properties [13-15]. Tissue-engineered heart valves strive to overcome the limitations of mechanical and bioprosthetic valves, because they are living tissues capable of active remodeling and self-repair [16]. However, more studies are required to determine the optimal composition, manufacturing technique, and biofunctionalization of the selected scaffolds [17]. Functional properties of mechanical heart valves may be addressed by additional coatings able to change the roughness and wettability of the product and control the resultant hemocompatibility and biocompatibility $[18,19]$. Promising results have been shown by de Avila et al. who reported zirconia material to possess optimal properties for biofilm formation [20]. Though the data were presented for dental implants, they seem to be promising for developing artificial heart valve.

Recent advances in polymer synthesis and processing have opened new fronts for developing novel materials with unique morphology, mechanical, and physical properties. The ability to control the material properties has given the light to develop medical devices of given patterns to address compelling needs of various medical fields, including cardiothoracic surgery [21,22]. Thus, superior polymeric materials may ensure the development of artificial heart valves able to replicate native valve function and overcome major limitations of commercially available prostheses [23]. Optimal polymeric heart valves should combine the main advantages of tissue and mechanical heart valve prostheses. Despite that the concept of the polymeric heart valve is not new and dates back to the 1950s, it has been put forward again with technologically advanced polymer synthesis and processing. The variety of polymers was used to design optimal flexible leaflets: polytetrafluoroethylene (PTFE and ePTFE) [24,25], silicone [26], polyurethanes [27], three-dimensionally cross-linked polyvinyl alcohol [28], POSS-PCU nanocomposite [29], copolymers based on styrene and isobutylene (SIBS) [30], and others. However, almost all of them have several drawbacks limiting them from successful clinical introduction.

Poly (Styrene-block-IsoButylene-block-Styrene) (SIBS) is a biostable thermoplastic elastomer with physical properties that overlap silicone rubber and polyurethane [31]. It was first developed in the Akron University, Ohio, USA in the late 1990s and was commercialized by Boston Scientific Corporation's (BSC; Natick, MA, USA) in 2002. The development of the Drug Eluting TAXUS Coronary Stent reduced the rate of the bypass procedures with the subsequently improved rate of complications. Spurred by superior TAXUS results, Innovia LLC started working on its application for manufacturing polymeric heart valve able to mimic native valve and fully replicate its function. Original SIBS was reported to be highly hemocompatible material, but its poor physical properties forwarded the research groups towards its reinforcement. Galloher et al. assessed effective fiber reinforcement (Dacron vs. LARS $^{\circledR}$ ) to improve the fatigue resistance of SIBS by minimizing stress concentration in the matrix. LARS ${ }^{\circledR}$-reinforced valve demonstrated superior physical properties over Dacron-reinforced valve, but they were still not enough to eradicate the main problem [32]. Wang et al. (2010) tested dimyristoyl phosphatidylcholine (DMPC) precoating of SIBS [33]. Despite good hemocompatibility, inferior functional properties limited its use for manufacturing polymeric heart valve potentially suitable for the clinical practice. Although several researches have been done on SIBS, no study to date 
has performed comprehensive assessment of its properties as a potential material for manufacturing heart valve leaflets and has compared with Gore-tex ${ }^{\mathrm{TM}}$, a benchmark material routinely used in the clinical practice.

Thus, our research is aimed at assessing physical properties, hemocompatibility and biocompatibility of SIBS to set reference range for selecting optimal nanofillers or functional fragments able to reinforce its structure, improve hemocompatibility and its application potential for manufacturing polymeric heart valve leaflets.

In order to achieve the set aim, we synthesized SIBS with $M_{n}$ of 33,000 and compared its properties with Gore-tex ${ }^{\mathrm{TM}}$, a polymer that is routinely used for manufacturing medical devices for cardiothoracic surgery. Surface topography of both materials was described with scanning electron microscopy and atomic force microscopy. Uniaxial tension allowed describing the mechanical properties. The water contact angle was used to evaluate hydrophilicity/hydrophobicity of the study samples. Hemocompatibility was evaluated using cell lines (Ea.hy 926), donor blood, and in vivo.

\section{Materials and Methods}

\subsection{SIBS Synthesis}

Stabilized styrene (Sigma-Aldrich, St. Louis, MO, USA, >99\%) was treated with $10 \% \mathrm{KOH}$ aqueous solution, repeatedly washed with water, dried first with $\mathrm{CaCl}_{2}$ and then with $\mathrm{CaH}_{2}$, and, finally, distilled two times over $\mathrm{CaH}_{2}$ under reduced pressure. Methylene chloride and hexane (both from Ekos-1, chemically pure grade) were treated with sulphuric acid, washed with aqueous sodium bicarbonate, dried over $\mathrm{CaCl}_{2}$, and distilled twice from $\mathrm{CaH}_{2}$ under an inert atmosphere Titanium tetrachloride (Sigma-Aldrich, St. Louis, MO, USA, 99.9\%) was distilled before use. Isobutylene (Sigma Aldrich, St. Louis, MO, USA; 99\%) was dried in the gaseous state by passing through the column packed with drierite and condensed into the Schlenk tube. 2,6-Di(tert-butyl)pyridine (Sigma-Aldrich, St. Louis, MO, USA; 97\%) and dicumyl alcohol (Sigma Aldrich, St. Louis, MO, USA; 97\%) were used as received. Dicumyl chloride was synthesized by passing gaseous $\mathrm{HCl}$ through solution of dicumyl alcohol in $\mathrm{CH}_{2} \mathrm{Cl}_{2}$ at $0{ }^{\circ} \mathrm{C}$ [34]. The purity of dicumyl chloride was conformed by ${ }^{1} \mathrm{H} \mathrm{NMR}$ spectroscopy to be $>99 \%$.

Triblock copolymer of isobutylene and styrene (SIBS) was synthesized by the living cationic polymerization according to the method reported by Mishra et al. [34]. Polymerization was performed under inert argon atmosphere in a three-necked flask. The reactor was consequently charged with dicumyl chloride $(0.095 \mathrm{mmol}), 25 \mathrm{~mL}$ of solvents (hexane-methylene chloride mixture $60: 40 \mathrm{v} / \mathrm{v}$ ), 2,6-di(tert-butyl)pyridine $(0.20 \mathrm{mmol})$, and isobutylene $(24 \mathrm{mmol})$ at $-60^{\circ} \mathrm{C}$. Then, the reaction mixture was cooled to $-80^{\circ} \mathrm{C}$ and $1.9 \mathrm{mmol}$ of titanium tetrachloride was added to initiate the polymerization. After $25 \mathrm{~min}$ since the beginning of the polymerization, $9.2 \mathrm{mmol}$ of a preliminarily cooled $2.0 \mathrm{M}$ solution of styrene in a hexane-methylene chloride mixture 60:40 v/v was added into the reactor. The reaction was quenched by $2.0 \mathrm{~mL}$ of prechilled methanol $50 \mathrm{~min}$ after the initiation. The product was precipitated twice into a tenfold excess of cooled ethanol. The cooled sample was separated by centrifugation, washed with a small amount of ethanol, and dried in a vacuum at $55-60{ }^{\circ} \mathrm{C} / 2 \mathrm{mmHg}$ to constant weight.

The structure of newly synthesized SIBS was identified with the differential scanning calorimetry (DSC). The phase and relaxation transitions of the polymer were studied by differential scanning calorimetry on DSC 3+ (Mettler Toledo, Greifensee, Switzerland) with a liquid nitrogen cooling system in the range of $-100-160^{\circ} \mathrm{C}$ with a heating rate of $20 \mathrm{deg} / \mathrm{min}$ and a cooling rate of $20 \mathrm{deg} / \mathrm{min}$ and with a nitrogen flow of $50 \mathrm{~mL} / \mathrm{min}$. The first and second heating cycles were examined in thermograms, the glass transition temperature $\mathrm{Tg}$ was evaluated by analyzing the inflection point.

Number-average molecular weight and polydispersity of SIBS were determined by gel permeation chromatography (GPC). Measurements were performed using an Ultimate 3000 (Thermo Fisher Scientific Dionex, Sunnyvale, CA, USA) device with a PLgel MIXED-C column $(7.5 \times 300 \mathrm{~mm}$, particle 
size $5 \mu \mathrm{m}$, Agilent Technologies, Santa Clara, CA, USA) column and one precolumn (PLgel $5 \mu \mathrm{m}$ Guard, Agilent Technologies, Santa Clara, CA, USA) thermostated at $30{ }^{\circ} \mathrm{C}$. GPS traces were achieved using a refractometer or a UV-detector $(\lambda=255 \mathrm{~nm})$. Tetrahydrofuran was used as a mobile phase with a flow rate of $1.0 \mathrm{~mL} \mathrm{~min}^{-1}$. The molecular weights and polydispersity were calculated based on polystyrene standards (EasiCal, Agilent Technologies, Santa Clara, CA, USA) with $\mathrm{M}_{\mathrm{w}} / \mathrm{M}_{\mathrm{n}} \leq 1.05$ and using Chromeleon 7.0 program (Thermo Fisher Scientific Dionex, Sunnyvale, CA, USA).

\subsection{SIBS and Gore-Tex ${ }^{T M}$ Samples}

The SIBS films were solvent cast. 1,6 $\mathrm{g}$ of SIBS pellets were dissolved in $8 \mathrm{~mL}$ of chloroform (Sigma-Aldrich, St. Louis, MO, USA, $\geq 99 \%$ ). The polymer solution was cast into a petri dish with the surface area of $21 \mathrm{~cm}$. Slow evaporation was processed at room temperature for $1 \mathrm{~h}$ and at $35^{\circ} \mathrm{C}$ for $3 \mathrm{~h}$. The resultant films were then vacuum dried for $24 \mathrm{~h}$ at room temperature and pressure of $<0.133$ mbar using FREEZONE 2.5 (Labconco, Kansas City, MO, USA). The thickness of the obtained films was $240 \mu \mathrm{m}$.

A commercial thin-walled Gore-tex ${ }^{\mathrm{TM}}$ (Gore \& Associates, Inc., Newark, DE, USA) stretch vascular graft (5 $\mathrm{mm}$ in diameter and $10 \mathrm{~cm}$ in length) was used as the reference sample to set the range of physical and hemocompatible properties that are required for a cardiovascular implant. Gore-tex ${ }^{\mathrm{TM}}$ is expanded PTFE with a microporous structure and a high strength-to-weight ratio, biocompatibility, and high thermal resistance. It is manufactured by means of a heating, stretching, and extruding process [35].

\subsection{Mechanical Properties}

SIBS and Gore-tex ${ }^{\mathrm{TM}}$ samples were tested in uniaxial tension using a universal testing machine (Zwick/Roell, Zwick GmbH \& Co. KG, Ulm, Germany) equipped with a $50 \mathrm{~N}$ load cell according to the editorial rules of the ISO 37: 2017. Given the absence of any reinforcing fillers, fibers, and particles, SIBS referred to the isotropy group of materials and did not require any specific considerations of its orientation mode. Ten SIBS samples were tested for one tensile direction. In contrast, Gore-tex ${ }^{\mathrm{TM}}$ had remarkable anisotropy, and was cut in two mutually perpendicular directions, longitudinal and circumferential. Ten Gore-tex ${ }^{\mathrm{TM}}$ samples were tested for each tensile directions. Both sets of samples were cut to dumbbells with the narrow portion of $2 \mathrm{~mm}$ and of $10 \mathrm{~mm}$ length using type 1A blade according to the ISO 37: 2017. Samples were then mounted in Vulkollan grips in the "Zwick/Roell" (Zwick GmbH \& Co. KG, Ulm, Germany). Samples were subjected to one loading cycle of applied strain at a constant rate of $10 \mathrm{~mm} / \mathrm{min}$ until rupture. The tensile strength was measured with the maximum tensile stress (MPa), taking into account the cross-section area of the samples. Elastic deformation was assessed with the relative elongation adjusted to the elongation at break (\%) and Young's modulus (MPa). The last was determined in the range of small deformations corresponding to the range of physiological loading.

\subsection{Assessment of Surface Properties}

Surface structure of samples was assessed using scanning electron microscopy (SEM) and atomic force microscopy (AFM). Tapping mode atomic force microscopy was performed under standard laboratory conditions. Samples were cut into $5 \mathrm{~mm} \times 5 \mathrm{~mm}$ sizes, fixed on a flat metal tab and studied using a MultiMode 8 microscope (Bruker, Billerica, MA, USA) equipped with SNL-10 probes (Bruker, Billerica, MA, USA).

Three SIBS and three Gore-tex ${ }^{\mathrm{TM}}$ samples were cut into $5 \mathrm{~mm} \times 5 \mathrm{~mm}$ sizes. Samples were then mounted on the tabs using conductive tape and gold/palladium $(\mathrm{Au} / \mathrm{Pd})$ coating sputtered with an EM ACE200 (Leica Mikrosysteme GmbH, Wetzlar, Germany). Scanning electron microscopy was performed using a S-3400N microscope (Hitachi, Tokyo, Japan). Secondary electron images were obtained at accelerating voltage of $5 \mathrm{kV}$ and magnification of 5000 . 
The water contact angle was estimated using the sessile drop method. A drop of distilled water, approximately $15 \mu \mathrm{L}$, was dispensed on the flat platform and stabilized in during the same time for each measurement at room temperature. The obtained images were processed using the ImageJ Contact Angle plugin. The analysis was repeated eight times for each group of samples. An average contact angle with standard deviation (S.D.) was reported.

\subsection{In Vitro Cytotoxicity and Cell Viability Assessment}

The experiment was performed using the Ea.hy 926 cell line, a hybridoma made from human umbilical vein endothelial cells (HUVEC) and a human lung carcinoma cell line. Cell culture plastic was used as a control in the experiments. Samples of sterile matrices $(n=5$ each group, sterilized with ethylene oxide) were seeded with cells at a density of $2.0 \times 105 \mathrm{cells} / \mathrm{cm}^{2}$ and cultured for 5 days in DME/F12 medium (Sigma Aldrich, St. Louis, MO, USA) containing 1\% HEPES buffer (Hyclone, Logan, UT, USA), 10\% fetal bovine serum (Sigma Aldrich, USA), 1\% L-glutamine, 100 units/mL penicillin, $0.1 \mu \mathrm{g} / \mathrm{mL}$ streptomycin, $0.1 \mu \mathrm{g} / \mathrm{mL}$ amphotericin $\mathrm{B}$, and hypoxanthine-aminopterin-thymidine (HAT; Sigma Aldrich, St. Louis, MO, USA) at $37^{\circ} \mathrm{C}$ and $5 \% \mathrm{CO}_{2}$. The medium was changed every alternative once in 2 days. The absolute number of cells per $1 \mathrm{~mm}^{2}$ surface and the relative amount of dead cells were assessed using a fluorescence microscope (Axio Observer Z1, Carl Zeiss, Oberkochen, Germany) after adding Hoechst 33342 nuclear fluorescent dyes (Molecular Probes, Eugene, OR, USA) in an amount of $2 \mu \mathrm{g} / \mathrm{mL}$ of ethidium bromide (EtBr; AppliChem, Darmstadt, Germany) at a concentration of $0.03 \mathrm{mg} / \mathrm{mL}$. Cells were calculated in five different fields at a magnification of $\times 200$ followed by a further counting under $1 \mathrm{~mm}^{2}$ of surface. The relative amount of dead cells was measured using the ratio of the absolute number of dead cells under $1 \mathrm{~mm}^{2}$ of surface to the absolute number of cells under $1 \mathrm{~mm}^{2}$ of surface. Cell proliferation was evaluated with sterile matrices ( $n=5$ each group) using Click-iT Plus EdU Imaging Kits (Molecular Probes, Eugene, OR, USA). Fluorescence microscopy was performed on an LSM 700 (Carl Zeiss) laser scanning microscope. The relative amount of proliferating cells was measured using the ratio of the absolute number of proliferating cells under $1 \mathrm{~mm}^{2}$ of surface to the absolute number of cells under $1 \mathrm{~mm}^{2}$ of surface.

\subsection{In Vitro Calcification Assessment}

Samples with width of $5 \mathrm{~mm} \times 5 \mathrm{~mm}$ ( $n=5$ each group) were placed in $2 \mathrm{~mL}$ solution based on DMEM medium (Sigma Aldrich, St. Louis, MO, USA) and serum albumin (FBS, Sigma Aldrich, St. Louis, $\mathrm{MO}, \mathrm{USA}$ ) containing $\mathrm{CaCl}_{2}$ and $\mathrm{Na}_{2} \mathrm{HPO}_{4}$ and kept in a $\mathrm{CO}_{2}$ incubator at $37{ }^{\circ} \mathrm{C}$ and $5 \%$ $\mathrm{CO}_{2}$. The degree of calcification was assessed 3 and 6 weeks after the incubation. Glutaraldehyde GA treated bovine xenopericardium (NeoCor, Russian Federation) was chosen as the positive control. Cryosections of the biomaterial and polymer samples were stained with alizarin red S (Reakhim, Moscow, Russian Federation) and evaluated with a light microscope (AXIO Imager A1 microscope, Carl Zeiss, Oberkochen, Germany).

\subsection{In Vivo Hemocompatibility Assessment}

In vivo inflammatory response and calcification were evaluated with the study samples of $5 \mathrm{~mm}$ $\times 5 \mathrm{~mm}$ in size implanted subcutaneously into male Wistar rats each weighting $55-70 \mathrm{~g}$ for two weeks (tissue response, $n=5$ ) and two months (tissue response, $n=5$; calcification, $n=5$ ). The study design was approved by the Local Ethics Committee of the Research Institute. The implants and surrounding tissues were excised once the experiment was completed and fixed in $4 \%$ formalin solution (MiniMed, Bryansk City, Russian Federation), then embedded in paraffin (Biovitrum, Saint-Petersburg, Russian Federation). Sections were stained with hematoxylin and eosin (Biovitrum, Saint-Petersburg, Russian Federation), according to Van Gieson (Biovitrum, Saint-Petersburg, Russian Federation) and alizarin red S (Reakhim, Moscow, Russian Federation). Samples were viewed with a light microscope (AXIO Imager A1, Carl Zeiss, Oberkochen, Germany). Inflammatory response was measured according to the editorial rules of the ISO 10993-6: 2016. The number of neovascularization foci was calculated in five 
different fields for each animal at a magnification of $\times 400$. Fibrous capsule thickness (the mean ten equally distributed measurements of perpendicular distance starting at the capsule-implant interface and moving outward), fatty infiltrate, and the number of lymph nodes were calculated to evaluate tissue response. The rest samples were subjected to hydrolysis in perchloric acid solution followed by heating to assess the amount of calcium (in case of the Gore-tex ${ }^{\mathrm{TM}}$ samples, calcifications formed during the experiment were present in the solution). The calcium content was measured with the inductively coupled plasma optical emission spectrometry using an iCAP 6500 DUO spectrometer (Thermo Fisher Scientific, Sunnyvale, CA, USA). GA-treated bovine xenopericardium (NeoCor, Kemerovo, Russian Federation) was the positive control.

\subsection{In Vitro Hemocompatibility Assessment}

The testing was performed in accordance with the editorial rules of the ISO 10993-4:2017. Fresh human donor blood samples were collected in $3.8 \%$ sodium citrate solution (dilution, nine parts of freshly drawn blood to one part sodium citrate solution). The citrated blood was centrifuged at $1000 \mathrm{rpm}$ at $25^{\circ} \mathrm{C}$ room for $10 \mathrm{~min}$ to obtain platelet-rich plasma (PRP). Platelet-poor plasma (PPP) was obtained by centrifuging the citrated blood at $4000 \mathrm{rpm}$ at room temperature. The polymer matrices from Gore-tex ${ }^{\mathrm{TM}}$ (Gore-Tex, Gore \& Associates, Inc., Newark, DE, USA) and polyethylene (LDPE) ERM-EC590 (Merck, Kenilworth, NJ, USA) were controls.

\subsection{Degree of Hemolysis}

Samples of $25 \mathrm{~cm}^{2}$ in size ( $n=5$ each material) were placed in the beakers, then $10 \mathrm{~mL}$ of physiological saline was added, and the beakers were placed in a thermostat at $37^{\circ} \mathrm{C}$ for $120 \mathrm{~min}$. $200 \mu \mathrm{L}$ of citrated blood was added, mixed, and then kept for $60 \mathrm{~min}$. After incubation, the solution was taken from the cups into tubes, followed by centrifugation at $2800 \mathrm{rpm}$ for $10 \mathrm{~min}$ to precipitate red blood cells (RBCs). Saline and distilled water were used as negative and positive controls to assess the degree of hemolysis. The optical density of the solutions under study was measured at a wavelength of $545 \mathrm{~nm}$ using a GENESYS 6 spectrophotometer (Thermo Fisher Scientific, Sunnyvale, CA, USA) [36,37].

\subsection{Platelet Aggregation}

Intact platelet-rich plasma was used as the positive control in assessing the impact of polymers on platelet aggregation. Spontaneous platelet activation was measured using a semi-automatic 4-channel platelet aggregation analyzer ARAST 4004 (LABiTec, Ahrensburg, Germany). To initiate spontaneous aggregation in citrate blood, $\mathrm{Ca}^{+2}$ ions were reduced; the prepared $\mathrm{CaCl}_{2}$ solution with a molar concentration of $0.25 \mathrm{M}$ was used as a reagent. The ratio of the sample and reagent was $250 \mu \mathrm{L}$ PRP + $25 \mu \mathrm{L} \mathrm{CaCl}_{2}$. The contact time of the samples with PRP was 3 min $[37,38]$.

\subsection{Platelet Adhesion}

Polymer matrices sized $1 \mathrm{~cm}^{2}$ were incubated with $500 \mu \mathrm{L}$ of PRP at $37^{\circ} \mathrm{C}$ for $2 \mathrm{~h}$, then gently rinsed with phosphate-buffered saline (PBS) to remove non-adhered plasma components. Samples were then fixed in a $2 \%$ glutaraldehyde solution prepared in $0.1 \mathrm{M}$ phosphate buffer for $6 \mathrm{~h}$. Samples were dehydrated with ascending grades of alcohol (50\%,75\%, 95\%, and 100\%). Platelet adhesion was measured using the scanning electron microscopy. Adhesive properties of the surface were evaluated in eight randomly selected fields of view using the deformation index [36-38].

\subsection{Statistical Analysis}

The statistical analysis was performed using commercially available software package STATISTICA 6.0 (StatSoft, Inc., Tulsa, OK, USA). The non-parametric Mann-Whitney U test was used to assess statistically significant differences between two independent groups. A $p$ level of $<0.05$ was considered statistically significant. 


\section{Results}

\subsection{Gel Permeation Chromatography}

The final block copolymer had the number average molecular weight of $M_{n}=33000$ and polydispersity $\left(\mathrm{M}_{\mathrm{w}} / \mathrm{M}_{\mathrm{n}}\right)$ of 1.3. The formation of block copolymer was confirmed by the shifts of GPC trace into high molecular weight after the addition of styrene to living difunctional polyisobutylene (Figure 1). Moreover, the experimentally determined value of the number average molecular weight $\left(M_{n}=33,000 \mathrm{~g} / \mathrm{mol}\right)$ is correlated well with theoretical one $\left(M_{n}=33,500 \mathrm{~g} / \mathrm{mol}\right)$.

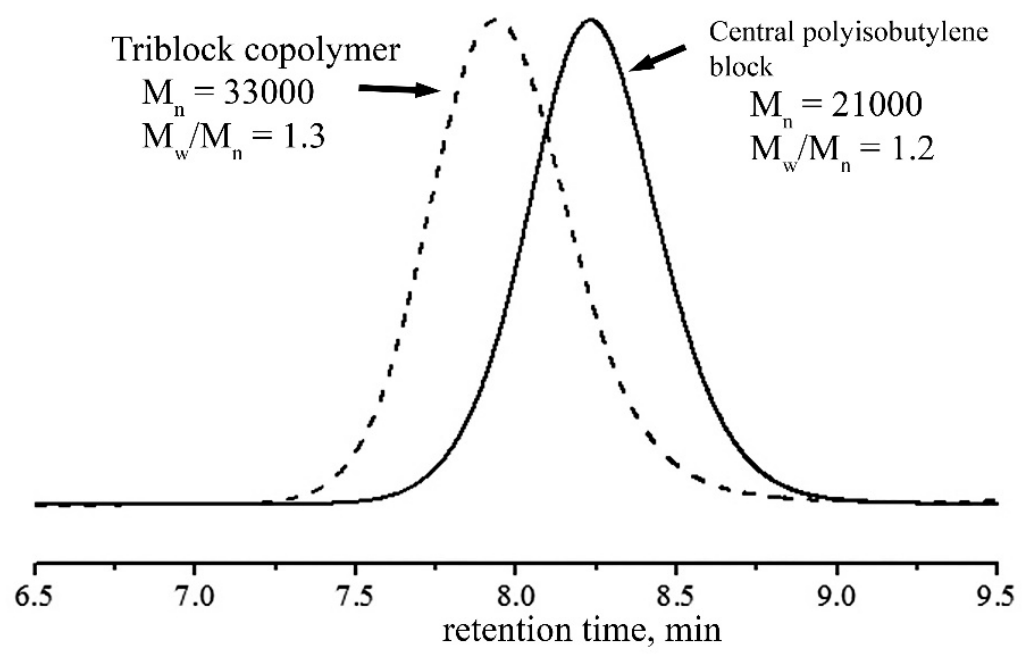

Figure 1. Typical gel permeation chromatography (GPC) curves of the samples.

\subsection{Differential Scanning Calorimetry}

The formation of block-copolymer was also confirmed by DSC (Figure 2). DSC clearly showed the glass transition temperature for polyisobutylene middle block at $-61.5^{\circ} \mathrm{C}$ as well as less pronounced transition at $87.7^{\circ} \mathrm{C}$ for polystyrene side blocks during the second heating run. The less pronounced glass transition for the polystyrene blocks was consistent with their low content in a triblock copolymer.

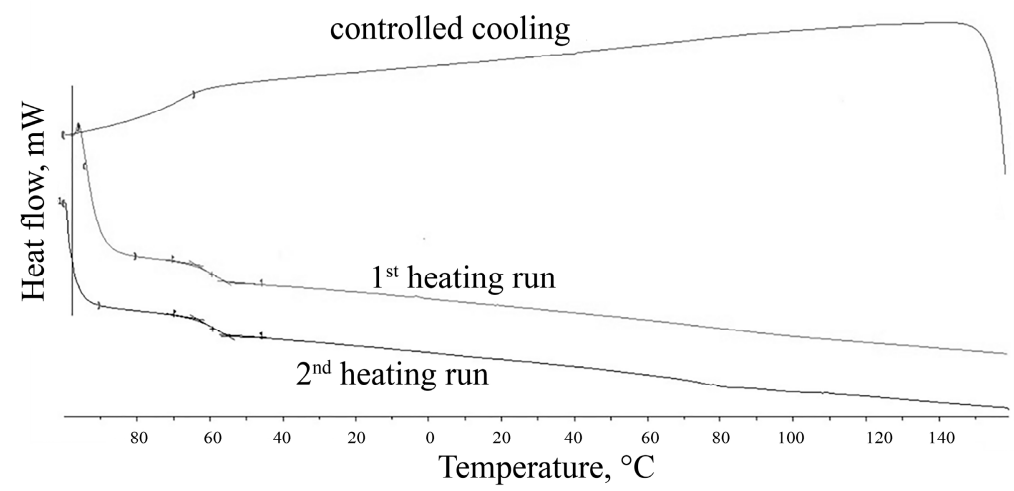

Figure 2. Differential scanning calorimetry (DSC) curves based on the heat flux versus temperature (two heating runs and controlled cooling).

\subsection{Physical and Mechanical Properties}

Gore-tex ${ }^{\mathrm{TM}}$ exceeded SIBS with a 6.6-fold increase in tensile strength for the longitudinal direction $(p<0.05)$ and a 4.6-fold for the circumferential direction $(p<0.05$; Figure 3$)$. 


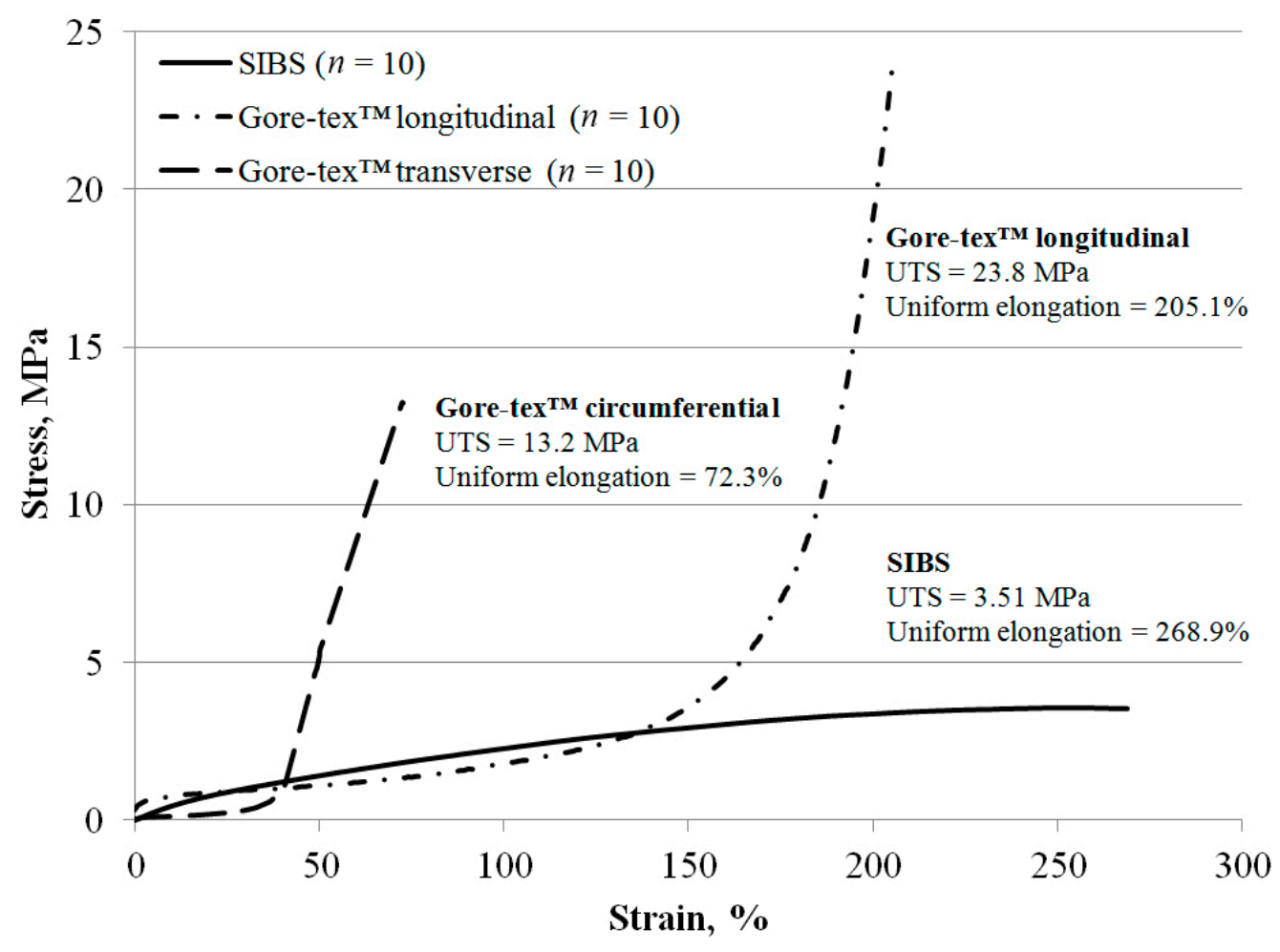

Figure 3. Mechanical properties of the study samples: stress (MPa), strain (\%), ultimate tensile strength (UTS, MPa), and uniform elongation (\%).

SIBS reported a 1.3- and a 3.0-fold increase in relative elongation at break and Young's modulus for the longitudinal direction as compared to that of Gore-tex ${ }^{\mathrm{TM}}$ and a 3.4-fold increase in the relative elongation for the transverse direction $(p<0.05)$. No significant differences had been found in SIBS and Gore-tex ${ }^{\mathrm{TM}}$ Young's modulus for the transverse direction $(p=0.62)$.

\subsection{Surface Topography}

Typical SEM and AFM images reported that both sides of SIBS samples (Figure 4C,D,G,H) had homogeneous patterns when compared with Gore-tex ${ }^{\mathrm{TM}}$ (Figure $4 \mathrm{~A}, \mathrm{~B}, \mathrm{E}, \mathrm{F}$ ) that had highly porous and regular structures (Figure 4). Importantly, the differences between the inner and outer surfaces of Gore-tex ${ }^{\mathrm{TM}}$ samples had been observed. The inner blood-contacting surface of Gore-tex ${ }^{\mathrm{TM}}$ was formed by large and porous structures as compared to its outer surface. None of these differences had been found for the inner and outer surfaces of SIBS.

The contact angles for the inner and outer surfaces of Gore-tex ${ }^{\mathrm{TM}}$ were similar $(p=0.62)$ suggesting its high hydrophobicity (Figure 4I,J). The contact angles for the inner and outer surfaces of SIBS (Figure $4 \mathrm{~K}, \mathrm{~L}$ ) did not differ significantly $(p=0.62)$. However, values obtained were lower than those for the Gore-tex ${ }^{\mathrm{TM}}$ samples $(p<0.05)$. The study materials were classified as hydrophobic (contact angle $>90$ ).

The contact angles for the inner and outer surfaces of Gore-tex ${ }^{\mathrm{TM}}$ were similar $(p=0.62)$. Obtained values confirmed its high hydrophobicity (Figure 4). The contact angles for the inner and outer surfaces of SIBS did not differ significantly $(p=0.62)$. However, the obtained values were lower than those for Gore-tex $^{\mathrm{TM}}(p<0.05)$. Both materials, SIBS and Gore-tex ${ }^{\mathrm{TM}}$, were considered hydrophobic (contact angle $>90)$. 


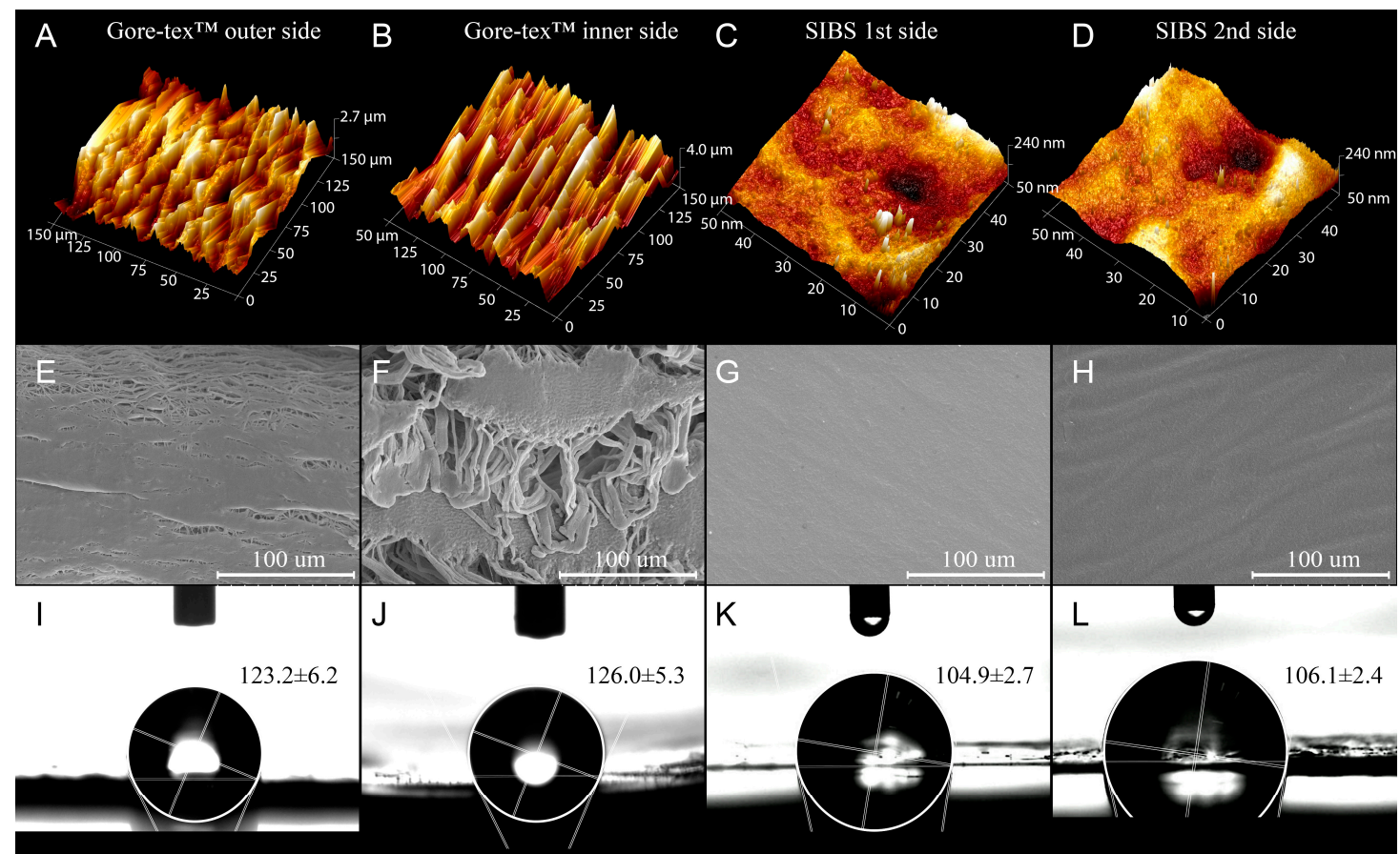

Figure 4. Typical AFM (A-D), SEM (E-H), and contact angle (I-L) images of Gore-tex ${ }^{\mathrm{TM}}$ and SIBS.

\subsection{In Vitro Biocompatibility}

There were no significant differences $(p=0.20)$ found in cell adhesion (Figure $5 \mathrm{~A}, \mathrm{~B}$ ) between SIBS (588 cells $\left.\mathrm{mm}^{2}\right)$ and cell culture plastic $\left(732 \mathrm{cells} / \mathrm{mm}^{2}\right.$ ). The last was considered the gold standard for assessing cell adhesion in vitro. The absolute number of adhered cells to SIBS was three times higher than that for Gore-tex ${ }^{\mathrm{TM}}\left(212\right.$ cells $\left./ \mathrm{mm}^{2} ; p<0.001\right)$.
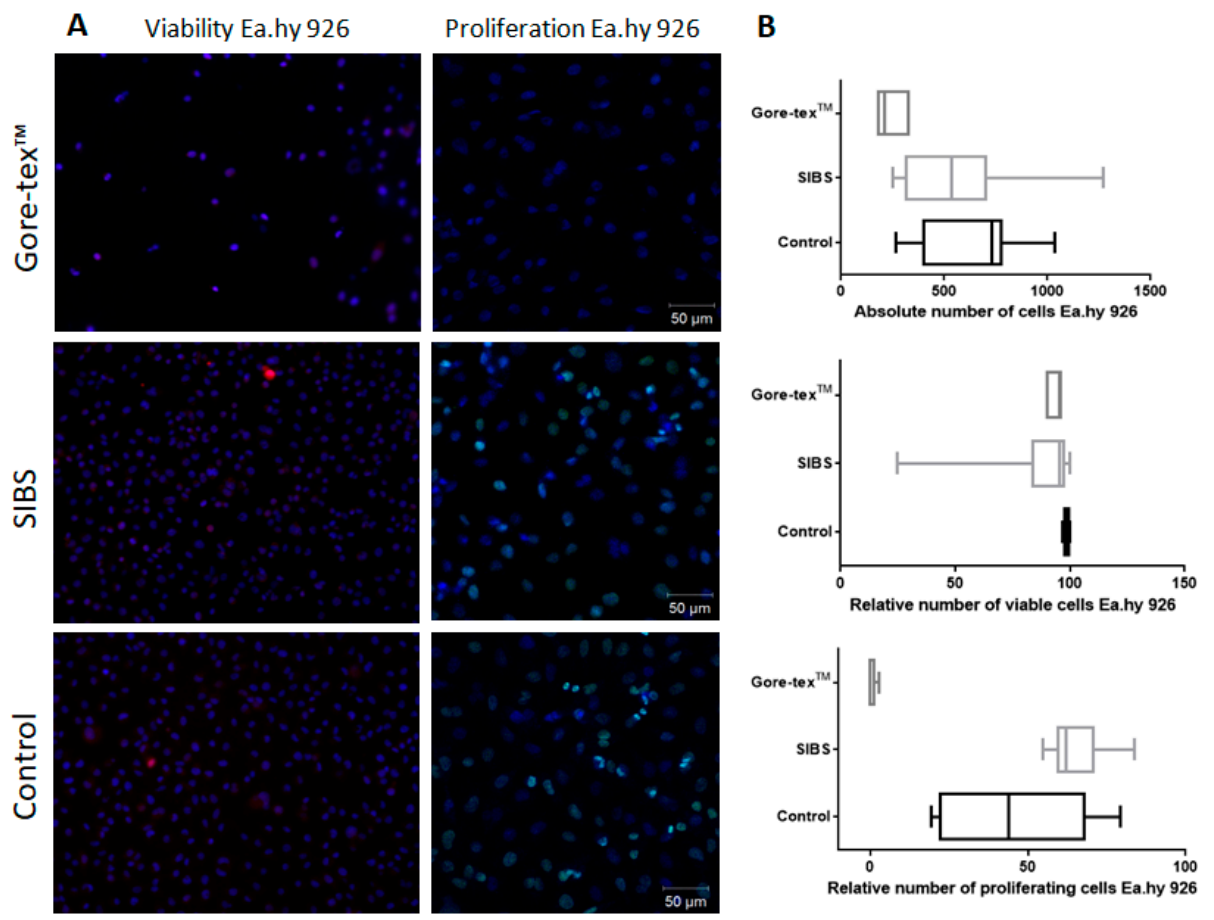

Figure 5. (A) Fluorescence microscopy of Gore-tex ${ }^{\mathrm{TM}}$, SIBS, and control (cell culture plastic) with cells: staining for cell viability, $\times 200$, staining for proliferation, $\times 200$. (B) Absolute number of cells, relative number of viable cells, relative number of proliferating cells Ea.hy 926 on the polymer surfaces. 
The relative number of viable Ea.hy 926 cells on different polymer matrices (Figure 5A,B) did not differ significantly $(p=0.56)$. SIBS and Gore-tex ${ }^{\mathrm{TM}}$ demonstrated the similar amounts of dead cells $(4.40 \%$ vs. $4.72 \%$, respectively; $p=0.93)$. However, cell culture plastic had a lower amount of dead cells than that of polymer matrices and accounted for $1.16 \%$ (Figure $5 \mathrm{~A} ; p<0.05$ ).

Poor cell proliferation on Gore-tex ${ }^{\mathrm{TM}}(0.10 \%)$ led to the failure of cell adhesion and proliferation (Figure 5A,B). SIBS demonstrated the highest proliferative activity of the Ea.hy 926 cell line $(62.04 \%)$, which was 1.4-fold higher of that on cell culture plastic $(44.00 \%, p<0.05)$.

\subsection{In Vitro Calcification}

SIBS and Gore-tex ${ }^{\mathrm{TM}}$ reported resistance to calcification (Figure $6 \mathrm{~B}, \mathrm{C}$ ) in the in vitro model, whereas biomaterial demonstrated severe calcification during the experiment (Figure 6A).

$\mathrm{GA}$

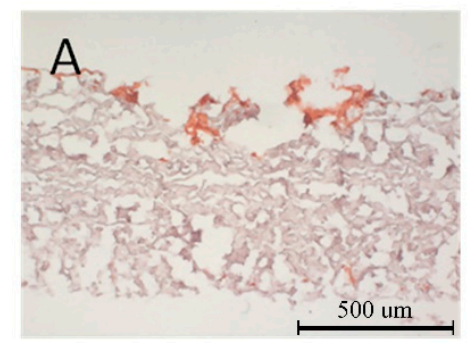

SIBS

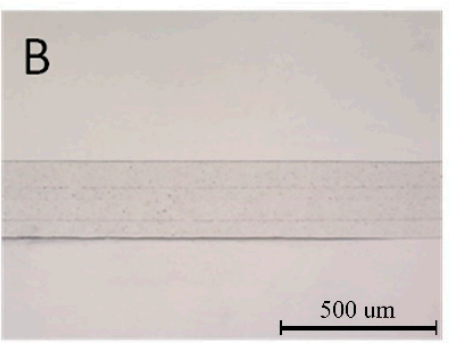

Gore-tex $^{\mathrm{TM}}$

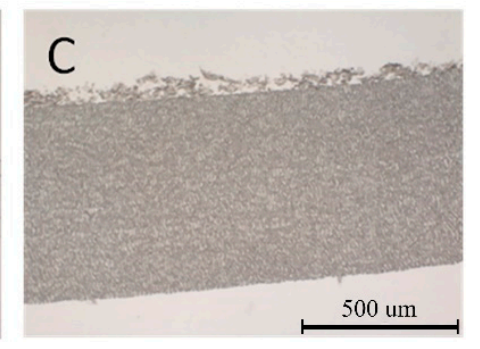

Figure 6. Typical light microscopy, calcification assessed in the in vitro model, 6-week incubation period; materials under study: (A) GA-treated bovine xenopericardium, (B) SIBS, and (C) Gore-tex ${ }^{\mathrm{TM}}$, $\times 100$ magnification.

\subsection{Tissue Response in the Rat Model}

Moderate macrophage response and the absence of giant cells were detected at day 14 after the implantation (Figure 7A-C). Lymph nodes in the surrounding tissues were found in all samples, suggesting the initiation of the inflammatory process. However, it was less pronounced in SIBS. Histological studies showed the formation of loose fibrous connective tissue of $69 \mu \mathrm{m}$ thick covering Gore-tex ${ }^{\mathrm{TM}}$ samples. The thickness of fibrous connective tissue in GA-treated xenopericardium and SIBS was $50 \mu \mathrm{m}$ and $98 \mu \mathrm{m}$, respectively. GA-treated xenopericardium had fatty infiltration surrounded by collagen fibers. All the samples had similar degree of neovascularization with mild capillary proliferation and one to three foci of neovascularization with fibroblast structures in the viewing field ( $\times 400$ magnification). GA-treated xenopericardium and Gore-tex ${ }^{\mathrm{TM}}$ had cellular infiltration, particularly active in the former sample. 

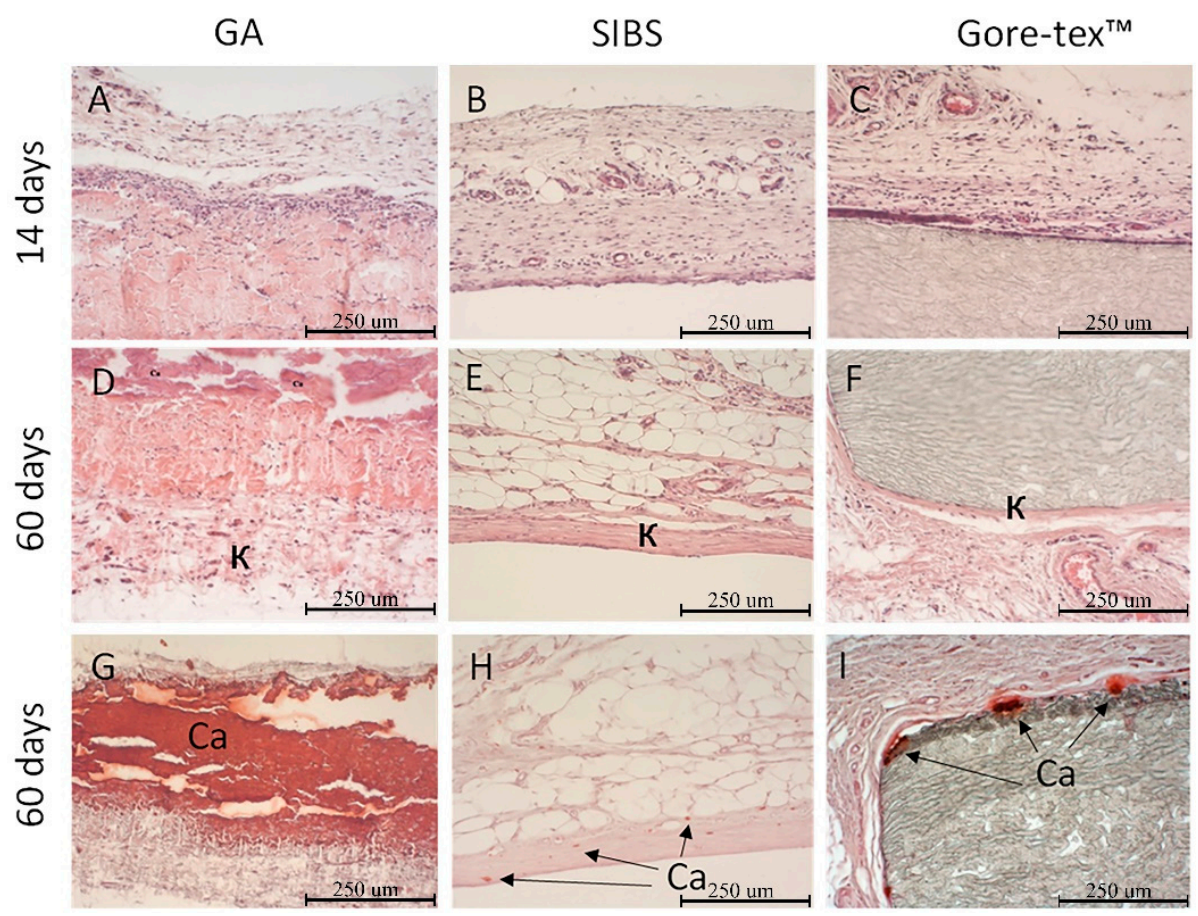

Figure 7. Histological sections $(\times 200)$ of $(\mathbf{A}, \mathbf{D}, \mathbf{G})$ GA-treated xenopericardium, $(\mathbf{B}, \mathbf{E}, \mathbf{H})$ SIBS, and $(\mathbf{C}, \mathbf{F}, \mathbf{I})$ Gore-tex ${ }^{\mathrm{TM}}$ following $(\mathbf{A}-\mathbf{C})$ the two-week and $(\mathbf{D}-\mathbf{F})$ two-month implantation into rats. The samples were stained with $(\mathbf{A}-\mathbf{F})$ hematoxylin-eosin and $(\mathbf{G}-\mathbf{I})$ alizarin red $\mathrm{S}$.

At 60 days following the implantation, dense connective tissue capsules consisting of collagen fibers with an average thickness of $42 \mu \mathrm{m}$ for Gore-tex ${ }^{\mathrm{TM}}$ and $58 \mu \mathrm{m}$ for SIBS were found in the surrounding tissues (Figure 7E,F). The capsule was not clearly visualized in the GA-treated xenopericardum sample. Gore-tex ${ }^{\mathrm{TM}}$ and GA-treated xenopericardium reported the presence of foreign body giant cells.

SIBS proved its biocompatibility as compared to the reference samples according to the semiquantitative assessment (ISO 10993-6:2016), based on the analysis of tissue response (neovascularization, fibrosis, fatty infiltration).

\subsection{In Vivo Calcification}

Histological studies showed active calcification of GA-treated xenopericardium samples (Figure 7G). Calcific deposits were found on the surface of Gore-tex ${ }^{\mathrm{TM}}$ samples (Figure 7I). Isolated calcific deposits formed within the connective tissue capsule in SIBS samples. The results of the quantitative assessment reported reliable differences in the calcium content between SIBS and Gore-tex ${ }^{\mathrm{TM}}$ samples $(p<0.05)$. A significant increase in the amount of calcium was reported for GA-treated xenopericardium samples $(p<0.05$; Table 1$)$.

Table 1. Calcium content in the samples, $\mathrm{mg} / \mathrm{g}$.

\begin{tabular}{cccccc}
\hline Sample & Min & $\mathbf{2 5 \%}$ & Me & $\mathbf{7 5 \%}$ & Max \\
\hline SIBS & 0.23 & 0.23 & 0.39 & 0.51 & 0.55 \\
Gore-tex ${ }^{\mathrm{TM}}$ & 0.49 & 0.53 & 1.25 & 2.70 & 2.95 \\
GA-treated xenopericardium & 1.77 & 2.57 & 93.79 & 155.30 & 159.80 \\
\hline
\end{tabular}

\subsection{Hemolysis}

SIBS had lower proportion of lysed RBC as compared to Gore-tex ${ }^{\mathrm{TM}}(0.35 \%$ (min: 0.03 ; max: 0.60 ; 25\%: $0.11 ; 75 \%$ : 0.40 ) vs. $0.4 \%$ (min: $0.11 ; \max : 2.40 ; 25 \%: 0.31 ; 75 \%: 0.67$ ), $p<0.05$ ). RBC hemolysis after contacting with polyethylene was $1.82 \%$ (min: 1.16 ; max: $2.30 ; 25 \%: 1.41 ; 75 \%: 2.10$ ). There 
were none significant differences found in the severity of hemolysis between two groups of polymers (SIBS and Gore-tex ${ }^{\mathrm{TM}} ; p=0.57$ ). However, reliable differences had been found between two groups of polymers (SIBS and Gore-tex $\left.{ }^{\mathrm{TM}}\right)$ as compared to polyethylene $(p<0.05)$.

\subsection{Platelet Aggregation}

The maximum platelet aggregation of intact platelet-rich plasma (positive control) was $8.6 \%$ (min: 7.79\%; max: $15.91 \%$; 25\%: 8.02; 75\%: 10.12\%). The samples of platelet-rich plasma contacted with polyethylene showed platelet aggregation with a maximum peak of $73.40 \%$ ( $\min : 67.73 \%$; max: $82.74 \%$; 25\%: 72.35; 75\%: 78.99\%), whereas SIBS and Gore-tex ${ }^{\mathrm{TM}}$ had the maximum platelet aggregation of 18.11\% (min: $16.40 \%$; max: $23.78 \%$; $25 \%$ : $16.6675 \%$ : $20.42 \%$ ) and $22.74 \%$ (min: $18.6 \%$; $\max : 28.56 \%$; 25\%: 22.45; 75\%: $24.52 \%$ ), respectively. SIBS and Gore-tex ${ }^{\mathrm{TM}}$ had reliably lower maximum of platelet aggregation as compared to polyethylene $(p<0.05)$.

\subsection{Platelet Adhesion}

The deformity index of platelets adhered on the polyethylene surface was 3.61 (min: 2.0; max: 4.25; 25\%: 2.82; 75\%: 4.0; Figure 8). Platelets type IV were commonly found on its surface and accounted for $61.29 \%$ of the total number of adhered platelets. The deformity index of platelets adhered on the SIBS surface was 3.25 (min: 2.1; max: 4.0; 25\%: 3.06; 75\%: 3.69). Platelets type II-III prevailed on its surface and accounted for $61.63 \%$ and $8.4 \%$ of the total number of adhered platelets. The deformity index of platelets adhered to the Gore-tex ${ }^{\mathrm{TM}}$ surface was 3.76 (min: 3.0 ; max: $4.09 ; 25 \%$ : $3.29 ; 75 \%$ : 3.96). Platelets type III and type IV were commonly found on the Gore-tex ${ }^{\mathrm{TM}}$ surface and accounted for $41.54 \%$ and $26.76 \%$, respectively.
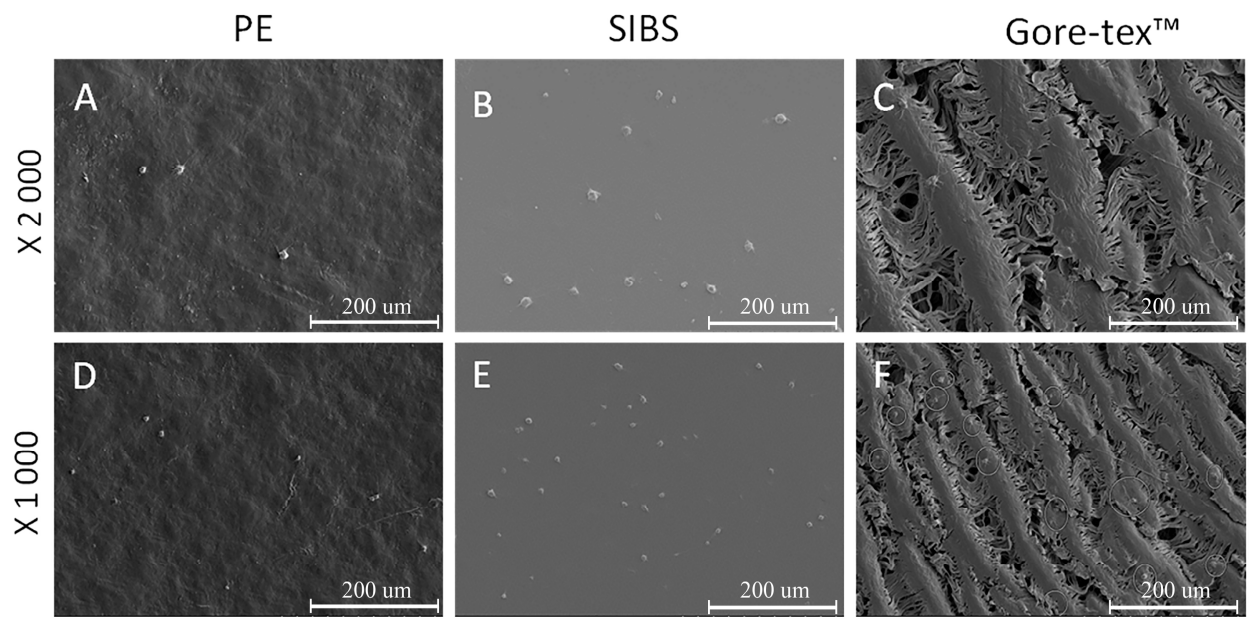

Figure 8. Platelet adhesion on the surface of polymer matrices made from $(\mathbf{A}, \mathbf{D})$ polyethylene, $(\mathbf{B}, \mathbf{E})$ SIBS, and (C,F) Gore-tex ${ }^{\mathrm{TM}}$.

There were none statistically significant differences found in the deformity indices of platelets adhered on SIBS and Gore-tex ${ }^{\mathrm{TM}}$ as compared to polyethylene ( $p=0.54$ and $p=0.72$, respectively).

\section{Discussion}

The development of polymeric heart leaflets requires the use of polymers with superior hemocompatible properties as well as those yielding the best physical and mechanical properties. Molecular and supramolecular architectures are of key importance and drive the choice of the proper polymer. All these requirements encourage the researchers to use co-polymeric materials and composite materials, particularly in biomedicine, due to their unique properties and the ability to combine structural fragments of various functional groups [13,39]. A particular attention should be paid to styrene and isobutylene block copolymers as promising materials since they are thermoplastic, 
elastic, possess high strength, and are resistant to hydrolytic and oxidative effects due to the carbon chain, biological inertness of the backbone and side chains (Figure 9) [40].

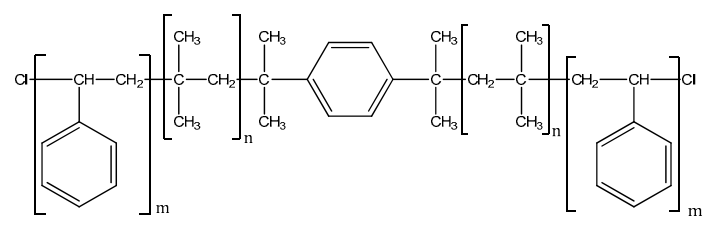

Figure 9. ABA block copolymers of isobutylene and styrene, structural formula.

There are three research groups developing flexible polymeric heart valves and leaflets from original or modified SIBS (i.e., with reinforced structure, added molecules, or following phospholipid modification) $[30,33,41]$. However, the existing commercial SIBS has some specific disadvantages, including viscoelastic creeping and a tendency to thrombi formation [31,42]. In order to meet the demands of cardiovascular surgery, it should possess unique properties [43]. By combining structural fragments of various types, we may obtain polymers with given patterns materials, i.e., hemocompatibility, biostability, increased strength, and optimal elasticity as compared with homopolymers [44]. We used the cationic polymerization method to synthesize SIBS with the preferred properties. This is the only method ensuring a simple introduction of additional units into the structure of the polymer molecule that can drastically improve the properties of the resultant material [45]. First, we analyzed the molecular weight characteristics of the polymer produced under the given conditions to assess the optimal parameters for the synthesis of a new molecule. Then, we synthesized the polymer with the number average molecular weight $\left(M_{n}\right)$ of 33,000 and polydispersity $\left(M_{w} / M_{n}\right)$ of 1.3 (Figure 1). Gore-tex ${ }^{\mathrm{TM}}$ was chosen as a control because it is currently applied in the real clinical practice when compared with other polymers undergoing experimental testing.

The mechanical properties of each block copolymer may vary depending on its molecular weight, the percentage of the constituent blocks, and the sequence of the polymer chain [46]. The strength of SIBS was lower than that of Gore-tex ${ }^{\mathrm{TM}}$. Despite the superior tensile strength of SIBS that exceeds the tensile strength of the native tissues (heart and vessels), it is worth considering that synthetic materials are not capable of regeneration. As a result, the accumulated fatigue stress can lead to the destruction of the material structure. It means that an optimal material should possess a significant margin of safety [36]. Due to this, the majority of researchers used SIBS polymers with $M_{n}$ of 60,000 or even more [36,46] with the ultimate tensile strength (MPa) of 10-30 and the ultimate elongation of $300-1100 \%$ [31]. However, a separate study covering this issue is required to enable the choice of the optimal molecular weight. The elasticity modulus in the physiological range of loading is considered as one of the key properties of the mechanical behavior of the material. It determines the suitability of the selected material to be used for developing artificial heart valves. More rigid polymers have a lower tendency to accumulate fatigue stress, but high rigidity of the leaflets may lead to significant hemodynamic alterations [37]. In our experiment SIBS demonstrated moderate rigidity between the biological material [38] and Gore-tex ${ }^{\mathrm{TM}}$. The elasticity of the leaflets ensures minimal energy losses during deformation of the heart valve under the pulsatile blood flow. Therefore, elastic and deformation properties should be considered as one of the main parameters in the decision-making process. Rigidity and elasticity can vary depending on the mass fraction of styrene in the polymer. An increase in rigidity and decrease in elongation is associated with increased styrene rate, and vice versa [46]. SIBS synthesized in this study demonstrated promising results in terms of rigidity. However, its structure may be altered in case elasticity may require the further optimization.

Hydrophobic surfaces are less hemocompatible, since they have a greater tendency to irreversible adsorption of proteins, including the resultant conformational changes, unlike hydrophilic surfaces, which minimally affect the conformation of proteins [40]. Hydrophilicity/hydrophobicity determines the subsequent adhesion of blood cells and cell proliferation [47]. However, there is some evidence on using of hydrophobic biomaterials in cardiovascular implants, particularly Gore-tex ${ }^{\mathrm{TM}}$ in artificial 
heart valve leaflets, in clinical practice [48]. Our experimental data demonstrated the superiority of SIBS over Gore-tex ${ }^{\mathrm{TM}}$ suggesting the former beneficial potential for the application in the clinical practice. Our results are also consistent with the recent studies [49]. Since both types of blocks are hydrophobic, hydrophilicity of the SIBS surface may be increased by adding hydrophilic groups (for example, hydroxyl) or by surface modification [49]. At the same time, the need for such modification may be confirmed by the results of hemocompatibility tests, since the process of contacting with blood is known to be a multifactorial one. The surface properties of the implanted material may also affect its hemocompatibility. Smoother surfaces with regular structures are more biocompatible due to their ability to reduce the severity of the inflammatory process and the adhesion of blood cells [50,51]. SIBS demonstrated rather good biostability since there are no gas inclusions accelerating its biodegradation. The more pronounced porosity of the Gore-tex ${ }^{\mathrm{TM}}$ sample and its previously reported biocompatibility as compared to the SIBS sample suggest the superior potential of the last according to the surface relief. We might conclude that cast molding with chloroform as a solvent for manufacturing SIBS heart valve prostheses is comparable to THF casting and melting, the well-described methods in the literature [52].

High hemocompatibility of SIBS and Gore-tex ${ }^{\mathrm{TM}}$ was confirmed by cytotoxicity testing using HUVEC cell line. The preceding experiments with the L929 cell line (mouse fibroblasts) [53] also showed high cell viability on the Kaneka SIBS material. However, we used the HUVEC cell line as it suited more to the objectives of this study. The cell proliferative potential index can complement the functional activity of cells in short-term experiments, which are not able to demonstrate the full range of changes in cell viability [54]. The ability of cell adhesion and proliferation is critical for tissue-engineered heart valves, a novel trend that has recently emerged. Taking into account the obtained results, we concluded that SIBS has superior potential for the further use in the development of tissue-engineered structures unlike Gore-tex ${ }^{\mathrm{TM}}$. Moreover, SIBS has higher capacity for spontaneous endothelization. Recent literature data suggest that the presence of the methyl groups in the polymer compound structure does not contribute to the proliferation of cells adhered on the material surface [55].

Dense fibrous (connective tissue) capsule formation around the SIBS and Gore-tex ${ }^{\mathrm{TM}}$ samples indicates the completion of the inflammatory process following the 60-day implantation of the biostable materials. However, the fibrous capsule around the SIBS sample was thicker than that for the Gore-tex ${ }^{\mathrm{TM}}$ sample. The obtained results were consistent with the results of other experiments [52]. Therefore, the molecular weight of the polymer and the structural quantitative composition of the block copolymer did not affect the biocompatibility of the polymer in the short-term experiments. Connective tissue is formed around the artificial heart valve leaflets creating a protective barrier, separating foreign material from the body environment. Moreover, it ensures a tight connection with the aortic root to prevent paravalvular regurgitation and secure the device fixation. Foreign body giant cells visualized in the Gore-tex ${ }^{\mathrm{TM}}$ and GA-treated xenopericardium samples may secrete reactive oxygen species and other chemical agents, contributing to oxidative damage and destruction of the implanted devices [56]. There were no such cells found in the SIBS sample 60 days after the implantation. The biocompatibility of SIBS most likely is related to a thin $(10 \mathrm{~nm})$ layer of pure polyisobutylene covering the polymer surface contacting with biological tissues, while the polystyrene phases are buried within the material [57]. High biocompatibility of SIBS and Gore-tex ${ }^{\mathrm{TM}}$ has recently been confirmed in the experimental and clinical studies [48,58].

Calcification is the principal cause leading to stenosis of native and tissue aortic valves [6]. Polymers, unlike biological tissue, do not contain phosphorus-rich cellular garbage and destroyed collagen provoking the mineralization process. Therefore, they are more resistant to calcification. Our results demonstrated the absence of calcium crystals provoking calcification in the studied polymer samples. The results of the quantitative analysis of calcium content in the in vivo model reported higher calcium content in GA-treated xenopericardium (the positive control) as compared to the polymer materials. Our finding was consistent with the literature data [59]. Gore-tex ${ }^{\mathrm{TM}}$ demonstrated the presence of calcific deposits at the interface between the fibrous capsule and the polymer, while SIBS had isolated calcium crystals within the connective tissue capsule [60]. The obtained results 
suggest superiority of SIBS to Gore-tex ${ }^{\mathrm{TM}}$ in terms of minimal calcification rate, stating the benefits of the former for manufacturing synthetic heart valve prosthesis.

The evaluation of the level of RBC hemolysis induced by SIBS demonstrated the absence of toxic effects on RBCs. Gore-tex ${ }^{\mathrm{TM}}$, being the control sample, did not cause the destruction of RBC membrane. The level of RBC hemolysis after direct contact with polyethylene was $1.82 \%$, suggesting its thrombogenicity. The obtained data are consistent with the results of other studies on the impact of SIBS and Gore-tex ${ }^{\mathrm{TM}}$ on RBC hemolysis. The level of RBC hemolysis after contact with Gore-tex ${ }^{\mathrm{TM}}$ was also significantly lower than those for the positive control with $100 \%$ hemolysis $[41,61]$. The cationic polymerization method used to synthesize the block copolymer ensures the safety of the produced medical materials as it provides a high degree of monomer conversion. Moreover, none of the solvents and catalytic residues were identified in the resultant material after isolation procedure. Platelet adhesion is the initial stage of blood clot formation. Importantly, adhesion alone is not enough to trigger the thrombogenic cascade. Activated platelets are able to release substances into the blood that can lead to irreversible aggregation. The adhesion of platelets with a regular round shape that have not yet been deformed, does not carry a thrombogenic hazard, since the adsorption of platelets type I is reversible and they can be easily returned to the bloodstream [62]. Our results on the assessment of adhesion properties showed that platelets adhere to all polymers, regardless of their type. The mechanism of platelet adhesion on the surface of the studied materials can be determined through the potential difference of polymers and platelets, and platelet adhesion can follow the adhesion of protein components of the blood, in this case, the hydrophobicity of polymers plays a crucial role [4]. The presence of methyl groups (-CH3) and the styrene benzene ring in the SIBS structure may provoke both protein adhesion and platelet adhesion [56]. Measurement of the aggregation activity of SIBS and Gore-tex ${ }^{\mathrm{TM}}$ polymers showed statistically significant advantage over polyethylene. Polyethylene, being the positive control in this experiment, caused a significant increase in the level of aggregation as compared to SIBS and Gore-tex ${ }^{\mathrm{TM}}$. Apparently, polyethylene releases substances that irritate blood platelet and lead to the activation of the last followed by the release of aggregation inducers.

Our results confirm that no residual monomer components and catalysts were found in the resultant material. Hemolysis, adhesion, and platelet aggregation demonstrated high hemocompatibility of SIBS as compared to Gore-tex ${ }^{\mathrm{TM}}$. However, its mechanical properties require further improvement and may be addressed through the introduction of nanofillers or a new molecule in the chemical structure.

\section{Conclusions}

SIBS with $\mathrm{M}_{\mathrm{n}}$ of 33,000 demonstrated similar hemocompatibility and biocompatibility to SIBS with $M_{n}$ of $60,000-150,000$. The properties of our polymer were superior over Gore-tex ${ }^{\mathrm{TM}}$ routinely used in the clinical practice. However, it was inferior in terms of mechanical properties. Obtained findings proved that its beneficial potential might be improved by increasing the ultimate tensile strength and uniform elongation through the nanofiller introduction or through an increase in the molecular weight of the block copolymer and/or modification of the central polyisobutylene block due to the introduction of methyl styrene units. SIBS modification enables the material to replicate native leaflet functions with a minimal risk for perforations, leaflet stress accumulation, ruptures, and tears.

Author Contributions: Conceptualization, E.O. and L.B.; Methodology, M.R., P.N., S.K.; Software, K.K.; Investigation, E.O., M.R., P.N., S.K., T.G., L.A., T.A., D.S., E.K., K.K., D.T.; Resources, Y.K.; Writing-Original Draft Preparation, E.O., M.R., P.N., S.K., K.K.; Writing-Review and Editing, E.O., M.R., P.N., L.B.; Supervision, E.O., P.N., S.K., L.B.; Project Administration, E.O.

Funding: The research was funded by a grant from the Russian Science Foundation (project No. 18-75-10061).

Conflicts of Interest: The authors declare no conflict of interest. 


\section{References}

1. Chen, Y.; Yiu, K.H. Growing importance of valvular heart disease in the elderly. J. Thorac. Dis. 2016, 8, E1701-E1703. [CrossRef] [PubMed]

2. D'Arcy, J.L.; Coffey, S.; Loudon, M.A.; Kennedy, A.; Pearson-Stuttard, J.; Birks, J.; Frangou, E.; Farmer, A.J.; Mant, D.; Wilson, J.; et al. Large-scale community echocardiographic screening reveals a major burden of undiagnosed valvular heart disease in older people: The OxVALVE Population Cohort Study. Eur. Heart J. 2016, 37, 3515-3522. [CrossRef] [PubMed]

3. Manji, R.A.; Ekser, B.; Menkis, A.H.; Cooper, D.K.C. Bioprosthetic heart valves of the future. Xenotransplantation 2014, 21, 1-10. [CrossRef] [PubMed]

4. Jaffer, I.H.; Whitlock, R.P. A mechanical heart valve is the best choice. Heart Asia 2016, 8, 62-64. [CrossRef]

5. Poli, D.; Antonucci, E.; Pengo, V.; Migliaccio, L.; Testa, S.; Lodigiani, C.; Coffetti, N.; Facchinetti, R.; Serricchio, G.; Falco, P.; et al. Italian Federation of Anticoagulation Clinics. Mechanical prosthetic heart valves: Quality of anticoagulation and thromboembolic risk. The observational multicenter PLECTRUM study. Int. J. Cardiol. 2018, 267, 68-73. [CrossRef]

6. Lee, S.; Levy, R.J.; Christian, A.J.; Hazen, S.L.; Frick, N.E.; Lai, E.K.; Grau, J.B.; Bavaria, J.E.; Ferrari, G. Calcification and Oxidative Modifications Are Associated with Progressive Bioprosthetic Heart Valve Dysfunction. J. Am. Heart Assoc. 2017, 6, e005648. [CrossRef]

7. Cartlidge, T.R.G.; Doris, M.K.; Sellers, S.L.; Pawade, T.A.; White, A.C.; Pessotto, R.; Kwiecinski, J.; Fletcher, A.; Alcaide, C.; Lucatelli, C.; et al. Detection and Prediction of Bioprosthetic Aortic Valve Degeneration. J. Am. Coll. Cardiol. 2019, 73, 1107-1119. [CrossRef]

8. Yang, J.M.; Olanrele, O.S.; Zhang, X.; Hsu, C.C. Fabrication of Hydrogel Materials for Biomedical Applications. In Novel Biomaterials for Regenerative Medicine (Advances in Experimental Medicine and Biology); Chun, $\mathrm{H}$., Park, K., Kim, C.H., Khang, G., Eds.; Springer: Singapore, 2018; Volume 1077, pp. 197-224.

9. Hasan, A.; Soliman, S.; El Hajj, F.; Tseng, Y.T.; Yalcin, H.C.; Marei, H.E. Fabrication and In Vitro Characterization of a Tissue Engineered PCL-PLLA Heart Valve. Sci. Rep. 2018, 8, 8187. [CrossRef]

10. Demetzos, C.; Pippa, N. (Eds.) Thermodynamics and Biophysics of Biomedical Nanosystems: Applications and Practical Considerations; Springer: Singapore, 2019; p. 475.

11. Cohn, D.; Sloutski, A.; Elyashiv, A.; Varma, V.B.; Ramanujan, R. In situ generated medical devices. Adv. Healthc. Mater. 2019, 8, 1801066. [CrossRef]

12. Piconi, C. Bioinert Ceramics: State-of-the-Art. Key Eng. Mater. 2017, 758, 3-13. [CrossRef]

13. Vellayappan, M.V.; Balaji, A.; Subramanian, A.P.; John, A.A.; Jaganathan, S.K.; Murugesan, S.; Mohandas, H.; Supriyanto, E.; Yusof, M. Tangible nanocomposites with diverse properties for heart valve application. Sci. Technol. Adv. Mater. 2015, 16, 033504. [CrossRef] [PubMed]

14. Rozeik, M.M.; Wheatley, D.J.; Gourlay, T. Investigating the Suitability of Carbon Nanotube Reinforced Polymer in Transcatheter Valve Applications. Cardiovasc. Eng. Technol. 2017, 8, 357-367. [CrossRef] [PubMed]

15. Fan, X.; Yang, J.; Loh, X.J.; Li, Z. Polymeric Janus Nanoparticles: Recent Advances in Synthetic Strategies, Materials Properties, and Applications. Macromol. Rapid Commun. 2019, 40, e1800203. [CrossRef] [PubMed]

16. Amadeus, S.Z.; Grande-Allen, K.J. Heart valve tissue engineering for valve replacement and disease modeling. Curr. Opin. Biomed. Eng. 2018, 5, 35-41.

17. Blum, K.M.; Drews, J.D.; Breuer, C.K. Tissue-Engineered Heart Valves: A Call for Mechanistic Studies. Tissue Eng. Part B Rev. 2018, 24, 240-253. [CrossRef]

18. Zeng, H.; Jarvik, R.; Catausan, G.; Moldovan, N.; Carlisle, J. Diamond coated artificial cardiovascular devices. Surf. Coat. Technol. 2016, 302, 420-425. [CrossRef]

19. Bogacz, W.; Lemanowicz, M.; Al-Rashed, M.H.; Nakonieczny, D.; Piotrowski, T.; Wójcik, J. Impact of roughness, wettability and hydrodynamic conditions on the incrustation on stainless steel surfaces. Appl. Therm. Eng. 2017, 112, 352-361. [CrossRef]

20. De Avila, E.D.; Avila-Campos, M.J.; Vergani, C.E.; Spolidório, D.M.; de Assis Mollo, F., Jr. Structural and quantitative analysis of a mature anaerobic biofilm on different implant abutment surfaces. J. Prosthet. Dent. 2016, 115, 428-436. [CrossRef]

21. Singhal, P.; Adriana, L.; Butany, J. Bioprosthetic Heart Valves: Impact of Implantation on Biomaterials. ISRN Biomater. 2014, 2013, 728791. [CrossRef] 
22. Hasan, A.; Ragaert, K.; Swieszkowski, W.; Selimovic, S.; Paul, A.; Camci-Unal, G.; Mofrad, M.R.K.; Khademhosseini, A. Biomechanical properties of native and tissue engineered heart valve constructs. J. Biomech. 2014, 47, 1949-1963. [CrossRef]

23. Rotman, O.M.; Kovarovic, B.; Chiu, W.C.; Bianchi, M.; Marom, G.; Slepian, M.J.; Bluestein, D. Novel Polymeric Valve for Transcatheter Aortic Valve Replacement Applications: In Vitro Hemodynamic Study. Ann. Biomed. Eng. 2019, 47, 113-125. [CrossRef] [PubMed]

24. Quintessenza, J.A.; Jacobs, J.P.; Chai, P.J.; Morell, V.O.; Lindberg, H. Polytetrafluoroethylene bicuspid pulmonary valve implantation: Experience with 126 patients. World J. Pediatric. Congenit. Heart Surg. 2010, 1, 20-27. [CrossRef] [PubMed]

25. Hawreliak, J.A.; Lind, J.; Maddox, B.; Barham, M.; Messner, M.; Barton, N.; Jensen, B.J.; Kumar, M. Dynamic Behavior of Engineered Lattice Materials. Sci. Rep. 2016, 6, 28094. [CrossRef] [PubMed]

26. Chetta, G.E.; Lloyd, J.R. The design, fabrication and evaluation prosthetic heart valve. J. Biomech. Eng. 1980, 102, 34-41. [CrossRef]

27. Daebritz, S.H.; Fausten, B.; Hermanns, B.; Franke, A.; Schroeder, J.; Groetzner, J.; Autschbach, R.; Messmer, B.J.; Sachweh, J.S. New flexible polymeric heart valve prostheses for the mitral and aortic positions. Heart Surg. Forum 2004, 7, 525-532. [CrossRef]

28. Jiang, H.; Campbell, G.; Boughner, D.; Wand, W.K.; Quantz, M. Design and manufacture of a polyvinyl alcohol (PVA) cryogel tri-leaflet heart valve prosthesis. Med. Eng. Phys. 2004, 26, 269-277. [CrossRef]

29. Kidane, A.G.; Burriesci, G.; Edirisinghe, M.; Ghanbari, H.; Bonhoeffer, P.; Seifalian, A.M. A novel nanocomposite polymer for development of synthetic heart valve leaflets. Acta Biomater. 2009, 5, $2409-2417$. [CrossRef]

30. Claiborne, T.E.; Sheriff, J.; Kuetting, M.; Steinseifer, U.; Slepian, M.J.; Bluestein, D.J. In vitro evaluation of a novel hemodynamically optimized trileaflet polymeric prosthetic heart valve. Biomech. Eng. 2013, 135, 021021. [CrossRef]

31. Pinchuk, L.; Wilson, G.J.; Barry, J.J.; Schoephoerster, R.T.; Parel, J.M.; Kennedy, J.P. Medical applications of poly(styrene-block-isobutylene-block-styrene) (“SIBS”). Biomaterials 2008, 29, 448-460. [CrossRef]

32. Yin, W.; Gallocher, S.; Pinchuk, L.; Schoephoerster, R.T.; Jesty, J.; Bluestein, D. Flow-induced Platelet Activation in a St. Jude Mechanical Heart Valve, a Trileaflet Polymeric Heart Valve, and a St. Jude Tissue Valve. Artif. Organs 2005, 29, 826-831. [CrossRef]

33. Wang, Q.; McGoron, A.J.; Bianco, R.; Kato, Y.; Pinchuk, L.; Schoephoerster, R.T. In-vivo assessment of a novel polymer (SIBS) trileaflet heart valve. J. Heart Valve Dis. 2010, 19, 499-505. [PubMed]

34. Mishra, M.K.; Sar-Mishra, B.; Kennedy, J.P. New telechelic polymers and sequential copolymers by polyfunctional initiator-transfer agents (inifers) LI. Synthesis and characterization of anisole-terminated polyisobutylenes. Polym. Bull. 1986, 16, 47-53. [CrossRef]

35. Xue, L.; Greisler, H.P. Biomaterials in the development and future of vascular grafts. J. Vasc. Surg. 2003, 37, 472-480. [CrossRef] [PubMed]

36. Zhang, Y.; Tran, R.T.; Gyawali, D.; Yang, J. Development of Photocrosslinkable Urethane-Doped Polyester Elastomers for Soft Tissue Engineering. Int. J. Biomater. Res. Eng. 2011, 1, 18-31. [CrossRef]

37. Ayoub, S.; Ferrari, G.; Gorman, R.C.; Gorman, J.H.; Schoen, F.J.; Sacks, M.S. Heart Valve Biomechanics and Underlying Mechanobiology. Compr. Physiol. 2016, 6, 1743-1780.

38. Aguiari, P.; Fiorese, M.; Iop, L.; Gerosa, G.; Bagno, A. Mechanical testing of pericardium for manufacturing prosthetic heart valves. Interact Cardiovasc. Thorac. Surg. 2016, 22, 72-84. [CrossRef]

39. Bianco, A.; Di Federico, E.; Cacciotti, I. Electrospun poly( $\varepsilon$-caprolactone)-based composites using synthesized $\beta$-tricalcium phosphate. Polym. Adv. Technol. 2011, 22, 1832-1841. [CrossRef]

40. Falde, E.J.; Yohe, S.T.; Colson, Y.L.; Grinstaff, M.W. Superhydrophobic materials for biomedical applications. Biomaterials 2016, 104, 87-103. [CrossRef]

41. Brubert, J.; Krajewski, S.; Wendel, H.P.; Nair, S.; Stasiak, J.; Moggridge, G.D. Hemocompatibility of styrenic block copolymers for use in prosthetic heart valves. J. Mater. Sci. Mater. Med. 2016, 27, 32. [CrossRef]

42. Bezuidenhout, D.; Williams, D.F.; Zilla, P. Polymeric heart valves for surgical implantation, catheter-based technologies and heart assist devices. Biomaterials 2015, 36, 6-25. [CrossRef]

43. Lam, M.T.; Wu, J.C. Biomaterial applications in cardiovascular tissue repair and regeneration. Expert Rev. Cardiovasc. Ther. 2012, 10, 1039-1049. [CrossRef] [PubMed] 
44. Bhushan, B.; Schricker, S.R. A review of block copolymer-based biomaterials that control protein and cell interactions. J. Biomed. Mater. Res. Part A 2014, 102, 2467-2480. [CrossRef] [PubMed]

45. Wang, W.; Lu, W.; Goodwin, A.; Wang, H.; Yin, P.; Kang, N.-G.; Hong, K.; Mays, J.W. Recent Advances in Thermoplastic Elastomers from Living Polymerizations: Macromolecular Architectures and Supramolecular Chemistry. Prog. Polym. Sci. 2019, 95, 1-31. [CrossRef]

46. Storey, R.F.; Chisholmt, B.J. Morphology and physical properties of poly (styrene-b-isobutylene-b-styrene) block copolymers. Polymer 1996, 37, 2925-2938. [CrossRef]

47. Vogler, E.A. Protein adsorption in three dimensions. Biomaterials 2012, 33, 1201-1237. [CrossRef]

48. Nosal, M.; Poruban, R.; Valentík, P.; Sagat, M.; Nagi, A.S.; Kantorova, A. Initial experience with polytetrafluoroethylene leaflet extensions for aortic valve repair. Eur. J. Cardiothorac. Surg. 2012, 41, 1255-1257. [CrossRef]

49. Yuan, S.; Li, Y.; Luan, S.; Shi, H.; Yan, S.; Yin, J. Infection-resistant styrenic thermoplastic elastomers that can switch from bactericidal capability to anti-adhesion. J. Mater. Chem. B 2016, 4, 1081-1089. [CrossRef]

50. Ulery, B.D.; Nair, L.S.; Laurencin, C.T. Biomedical Applications of Biodegradable Polymers. J. Polym. Sci. Part B Polym. Phys. 2011, 49, 832-864. [CrossRef]

51. Chung, T.W.; Liu, D.Z.; Wang, S.Y.; Wang, S.S. Enhancement of the growth of human endothelial cells by surface roughness at nanometer scale. Biomaterials 2003, 24, 4655-4661. [CrossRef]

52. Fray, M.E.; Prowans, P.; Puskas, J.E.; Altsta, V. Biocompatibility and Fatigue Properties of Polystyrene-Polyisobutylene-Polystyrene, an Emerging Thermoplastic Elastomeric Biomaterial. Biomacromolecules 2006, 7, 844-850. [CrossRef]

53. Yuan, S.; Li, Z.; Zhao, J.; Luan, S.; Ma, J.; Song, L.; Shi, H.; Jin, J.; Yin, J. Enhanced biocompatibility of biostable poly(styrene-b-isobutylene-b-styrene) elastomer via poly(dopamine)-assisted chitosan/hyaluronic acid immobilization. RSC Adv. 2014, 4, 31481-31488. [CrossRef]

54. Lu, S.; Zhang, P.; Sun, X.; Gong, F.; Yang, S.; Shen, L.; Huang, Z.; Wang, C. Synthetic ePTFE grafts coated with an anti-CD133 antibody-functionalized heparin/collagen multilayer with rapid in vivo endothelialization properties. ACS Appl. Mater. Interfaces 2013, 5, 7360-7369. [CrossRef] [PubMed]

55. Thevenot, P.; Hu, W.; Tang, L. Surface chemistry influences implant biocompatibility. Curr. Top. Med. Chem. 2008, 8, 270-280. [PubMed]

56. Wiggins, M.J.; Wilkoff, B.; Anderson, J.M.; Hiltner, A. Biodegradation of polyether polyurethane inner insulation in bipolar pacemaker leads. J. Biomed. Mater. Res. 2001, 58, 302-307. [CrossRef]

57. Knoll, A.; Magerle, R.; Krausch, G. Tapping Mode Atomic Force Microscopy on Polymers: Where Is the True Sample Surface? Macromolecules 2001, 34, 4159-4165. [CrossRef]

58. Claiborne, T.E.; Slepian, M.J.; Hossainy, S.; Bluestein, D. Polymeric trileaflet prosthetic heart valves: Evolution and path to clinical reality. Expert Rev. Med. Devices 2012, 9, 577-594. [CrossRef]

59. Jee, K.S.; Kim, Y.S.; Park, K.D.; Kim, Y.H. A novel chemical modification of bioprosthetic tissues using L-arginine. Biomaterials 2003, 24, 3409-3416. [CrossRef]

60. Hilbert, S.; Ferrans, V.; Tomita, Y.; Eidbo, E.; Jones, M. Evaluation of explanted polyurethane trileaflet cardiac valve prostheses. J. Thorac. Cardiovasc. Surg. 1987, 94, 419-429.

61. Kakavand, M.; Yazdanpanah, G.; Ahmadiani, A.; Niknejad, H. Blood compatibility of human amniotic membrane compared with heparin-coated ePTFE for vascular tissue engineering. J. Tissue Eng. Regen. Med. 2017, 11, 1701-1709. [CrossRef]

62. Ye, X.; Wang, Z.; Zhang, X.; Zhou, M.; Cai, L. Hemocompatibility research on the micro-structure surface of a bionic heart valve. Biomed. Mater. Eng. 2014, 24, 2361-2369.

(C) 2019 by the authors. Licensee MDPI, Basel, Switzerland. This article is an open access article distributed under the terms and conditions of the Creative Commons Attribution (CC BY) license (http://creativecommons.org/licenses/by/4.0/). 